\title{
Dynamics of $\alpha$-Tubulin Deacetylation in Intact Neurons
}

\author{
Mark M. Black, Peter W. Baas, and Suzanne Humphries \\ Department of Anatomy, Temple University School of Medicine, Philadelphia, Pennsylvania 19140
}

The majority of the $\alpha$-tubulin in cultured neurons is acetylated (Black and Keyser, 1987). The present studies examine the relationships of the acetylation and deacetylation reactions to tubulin assembly and disassembly in intact neurons. Extraction assays which separate assembled and unassembled tubulin pools reveal that $\geq 99 \%$ of the total acetylated, as well as newly acetylated, tubulin is cytoskeletal associated. Treatment of neurons with depolymerizing drugs results in a progressive decrease in the levels of total tubulin in polymer and a corresponding increase in the levels of soluble tubulin. These drugs also cause a progressive decrease in the levels of acetylated $\alpha$-tubulin in polymer that closely parallels in rate and extent that of total $\alpha$-tubulin. However, there is no corresponding increase in soluble acetylated tubulin. Because the total levels of $\alpha$-tubulin remain unchanged during drug treatment, the decrease in levels of acetylated $\alpha$-tubulin during depolymerization must reflect its rapid conversion to nonacetylated $\alpha$-tubulin. These findings suggest $\alpha$-tubulin is acetylated in the polymeric form and that deacetylation is closely coupled to depolymerization.

The close coupling between $\alpha$-tubulin deacetylation and depolymerization provided a means of estimating the rate at which subunits cycle off microtubules in intact neurons. Acetate turnover on tubulin in intact neurons was determined both by pulse-chase protocols with ${ }^{3} \mathrm{H}$-acetate and by measuring the loss of acetylated subunits (using quantitative immunoblotting) under conditions of net microtubule depolymerization induced by colchicine. Both methods yielded similar results. Acetate turnover occurred biphasically; 30$50 \%$ of the acetate on tubulin turns over with a $t_{1 / 2}$ of $1.5-2$ $\mathrm{hr}$, and the remaining half or more turns over with a $t_{1 / 2}$ of 5$10 \mathrm{hr}$. We suggest that these kinetically distinguishable pools of acetylated $\alpha$-tubulin reflect distinct pools of acetylated microtubules that differ in their average rates of subunit turnover.

Eukaryotic cells contain an extensive array of fibrous elements which collectively make up the cytoskeleton. There are 3 major classes of fibrous elements: microtubules, intermediate filaments, and microfilaments. Each of these is a linear polymer of protein subunits. These polymers constitute major architectural elements that define the external shape of cells and also organize

\footnotetext{
Received Apr. 11, 1988; revised June 20, 1988; accepted June 21, 1988.

We thank Dr. Gianni Piperno of the Rockefeller University for generously providing the $\alpha$-tubulin antibodies required for the present studies, and the $\mathrm{Na}$ tional Products Branch of NCI for providing taxol. The present work was supported by NIH Grants to M.M.B.

Correspondence should be addressed to Dr. Mark M. Black, Department of Anatomy, Temple University School of Medicine, 3420 N. Broad Street, Philadelphia, PA 19140.

Copyright (C) 1989 Society for Neuroscience $0270-6474 / 89 / 010358-11 \$ 02.00 / 0$
}

their cytoplasm to carry out the variety of metabolic and motile processes that are essential to life.

In actively proliferating cells, the cytoskeletal networks are very dynamic, continually and rapidly changing their form during the mitosis-interphase transitions, as well as throughout interphase as the cells locomote within their environment. Recently, techniques involving microinjection of labeled cytoskeletal proteins have been used to quantify the dynamic behavior of cytoskeletal polymers in such cells. These studies, which have focused principally on tubulin, the core component of microtubules, showed that most microtubules exchange subunits relatively rapidly, with a $t_{1 / 2}$ of 5-20 min during interphase, and even faster during mitosis (Saxton et al., 1984; Schulze and Kirschner, 1986; Webster et al., 1987). A small portion of the microtubules are metastable, turning over with a $t_{1 / 2}$ of one or more hours (Schulze and Kirschner, 1987; Webster et al., 1988).

Relatively little information is available on cytoskeletal dynamics in cells that are postmitotic and that express a stable and polarized morphology. It seems reasonable that in such cells, the persistence of a polarized morphology will reflect, in part, an underlying stabilization of the cytoskeleton.

For the past several years, we have been studying the cytoskeleton of neurons, with the aim of identifying how it is specialized to provide for the highly asymmetric morphology of these cells. Neurons have long cytoplasmic extensions, termed axons and dendrites, which are specialized to receive, process, and transmit information over long distances within the organism. The ability of neurons to extend and maintain their axonal and dendritic neurites is essential to their morphological and functional differentiation.

Several earlier observations have suggested that the neuronal cytoskeleton is unusually stable, at least as judged by its relatively low sensitivity to drug- or temperature-promoted depolymerization. For example, when $\mathrm{PC} 12$ cells are induced to extend neurites by treatment with nerve growth factor (NGF), there is an accompanying stabilization of their microtubule network to the depolymerization-promoting action of colchicine and low temperature (Black and Greene, 1982). Also, in a variety of neurons, many microtubules are relatively insensitive to these and other depolymerizing agents (Morris and Lasek, 1982; Brady et al., 1984; see also Results). In all of these studies, microtubule stability was assessed following perturbation of the neurons. Thus, although it is clear that neuronal microtubules are relatively stable, the nature of their in situ dynamics has not been revealed. In the present work, we have combined drug experiments with a novel, noninvasive procedure to obtain information concerning subunit turnover in microtubules of intact neurons. These studies are based on analyses of acetate turnover on tubulin. $\alpha$-Tubulin is acetylated in neurons (Black and Keyser, 1987; Cambray-Deakin and Burgoyne, 1987), and in the cultured neurons that we study, most of the $\alpha$-tubulin is acet- 
ylated (Black and Keyser, 1987). We show here that acetylated tubulin of cultured neurons is a polymer-specific form of tubulin and that deacetylation is tightly coupled to depolymerization. Thus, the kinetics of acetate turnover on tubulin provide a useful approximation for the turnover of tubulin in the population of acetylated microtubules. This population of microtubules, in fact, represents most of the microtubule mass in neurons because the majority of $\alpha$-tubulin is acetylated in cultured neurons, and this tubulin is polymer specific. Turnover measurements of acetatc on these microtubules in intact neurons reveal 2 kinetically distinct populations: one population represents $50-70 \%$ of the acetylated subunits and turns over with a $t_{1 / 2}=5-10 \mathrm{hr}$, whereas the other population turns over with a $t_{1 / 2} \sim 2 \mathrm{hr}$.

\section{Materials and Methods}

Cell culture. Rat sympathetic neurons were dissociated from superior cervial ganglia of 0-to-5-d-old rat pups as described previously (Black et al., 1984). Cultures were maintained in HB101 medium (NEN, Boston), $1 \mathrm{~mm} \mathrm{Na}$ pyruvate, $2 \mathrm{~mm}$ glutamine, $50 \mathrm{U} / \mathrm{ml}$ penicillin and streptomycin, $10 \mu \mathrm{m}$ uridine, $10 \mu \mathrm{m}$ fluorodeoxyuridine, $50 \mathrm{ng} / \mathrm{ml} \mathrm{NGF}$, $5 \%$ human placental serum, and $2.5 \%$ fetal calf serum. Cytosine arabinoside $(2$ or $5 \mu \mathrm{M}$ ) was also included in the medium during the first week or longer to eliminate non-neuronal cells. The resulting cultures typically consisted of $\geq 90 \%$ neurons and were used after 10-14 $\mathrm{d}$ in vitro.

Effects of microtubule depolymerizing drugs on the levels of tubulin in cultured neurons. Appropriate volumes of stock solutions of colchicine, $2.5 \mathrm{~mm}$ in water, podophyllotoxin or nocodazol, $4.5 \mathrm{~mm}$ in dimethylsulfoxide, were added to cultures to achieve final concentrations of 25 and $4.5 \mu \mathrm{M}$, respectively. After incubation times ranging from 0 to 24 $\mathrm{hr}$, cultures were processed in 1 of 2 ways. For some experiments, cultured neurons were dissolved directly in $1 \%$ SDS containing 1 trypsin inhibitory unit $/ \mathrm{ml}$ of aprotinin and $10 \mu \mathrm{g} / \mathrm{ml}$ each of antipain, chymostatin, and leupeptin. In other experiments cultured neurons were fractioned into soluble and cytoskeletal fractions by extraction with Triton X-100 using previously published procedures (Black et al., 1986b). Whole-cell SDS extracts as well as soluble and cytoskeletal fractions were then assayed for various forms of tubulin by quantitative immunoblotting (see below).

Analysis of acetate lurnover on tubulin. Cultures were pulse-labeled with ${ }^{3} \mathrm{H}$-acetate (ICN, Costa Mesa, CA) as described previously (Black and Keyser, 1987). Briefly, cultures were rinsed twice with a balanced salt solution (BSS) (124 mM NaCl, $12 \mathrm{~mm} \mathrm{NaOH}, 30 \mathrm{~mm}$ HEPES, 2 $\mathrm{mM} \mathrm{CaCl}_{2}, 5 \mathrm{mM} \mathrm{KCl}, 0.5 \mathrm{~mm} \mathrm{MgCl}_{2}, 11 \mathrm{~mm}$ dextrose, $50 \mathrm{ng} / \mathrm{ml} \mathrm{NGF}$ ), incubated with fresh BSS for $30 \mathrm{~min}$ at $35^{\circ} \mathrm{C}$, and then incubated with fresh BSS containing $200 \mu \mathrm{Ci} / \mathrm{ml}$ of ${ }^{3} \mathrm{H}$-acetate, Na salt, for $90 \mathrm{~min}$. At the end of the labeling period, the medium was removed and replaced with complete $\mathrm{HB} 101$ medium supplemented with $2 \mathrm{~mm}$ unlabeled $\mathrm{Na}$ acetate to initiate the chase period. Control experiments established that the simultaneous addition of $2 \mathrm{~mm}$ unlabeled $\mathrm{Na}$ acetate and $200 \mu \mathrm{Ci}$ / $\mathrm{ml}{ }^{3} \mathrm{H}$-acetate to cultures was sufficient to completely block the incorporation of ${ }^{3} \mathrm{H}$-acetate into tubulin. Also, incorporation of ${ }^{3} \mathrm{H}$-acetate into $\alpha$-tubulin is linear over a $1 \mathrm{hr}$ incubation period, with no detectable lag in incorporation (data not shown). The absence of any detectable lag suggests that acetate in the medium rapidly gets into the cells and equilibrates with the intracellular pool. In the present studies, the chase medium contained unlabeled acetate at $\geq 100$-fold the concentration of the ${ }^{3} \mathrm{H}$-acetate used for labeling. At these levels, the unlabeled acetate should rapidly and effectively reduce incorporation of labeled acetate to negligible levels. At the end of the chase period, which ranged from 0 to $23 \mathrm{hr}$, cultures were rinsed twice with PBS, and then dissolved in $1 \%$ SDS as described above. We analyzed $100 \mu \mathrm{g}$ of protein from each culture in consecutive wells of slab gels, and the radioactivity associated with tubulin was quantified as described below.

Analysis of tubulin turnover in cultured neurons. For these experiments, cultures were pulse-labeled with ${ }^{35} \mathrm{~S}$-methionine (Amersham Corp., Arlington Heights, IL) and then chased in the absence of label for times ranging from 0 to $22 \mathrm{hr}$. Cultures were incubated for $1 \mathrm{hr}$ at $37^{\circ} \mathrm{C}$ in DME minus methionine and containing the same supplements as described above for HB101. The pulse was initiated by replacing the medium with fresh medium pre-equilibrated to $\mathrm{pH} 7.3$ and $37^{\circ} \mathrm{C}$ and containing $200 \mu \mathrm{Ci} / \mathrm{ml}^{35} \mathrm{~S}$-methionine. Labeling was carried out for 60 min, after which the labeled medium was removed from all cultures and replaced with $\mathrm{HB} 101$ containing all the supplements described above plus 10 times the normal level of unlabeled methionine. The cultures were incubated an additional $30 \mathrm{~min}$ to allow for the continued incorporation of labeled methionine that occurs following removal of the labeled medium. Cultures were then harvested at the end of this $30 \mathrm{~min}$ period and at varying times thereafter by scraping into $1 \%$ SDS as described above. We analyzed $100 \mu \mathrm{g}$ of total cell protein from the various cultures by isoelectricfocusing $\times$ SDS-PAGE, and the levels of ${ }^{35} \mathrm{~S}$-methionine-labeled tubulin were quantified as described below.

Immunoblotting. Quantitative immunoblotting was carried out to measure the relative levels of tubulin in control and drug-treated cultures. The procedures used were essentially as described by Drubin et al. (1985). In experiments involving analysis of whole-cell SDS extracts, equal amounts of protein from the control and drug-treated cultures were assayed. Protein levels were determined with the BCA assay (Pierce Chemical Co., Rockford, IL) using BSA as standard. After separation on $8.5 \%$ SDS-polyacrylamide gels, the samples were transferred to nitrocellulose paper (BA83, Schleicher and Schuell, Keene, NH) by the method of Towbin et al. (1979). The nitrocellulose transfers were blocked with $4 \%$ BSA in Tris-buffered saline (TBS; $50 \mathrm{~mm}$ Tris-HCl, pH 7.6, $200 \mathrm{mM} \mathrm{NaCl}$ ) and then probed with monoclonal antibodies specific for $\beta$-tubulin, total $\alpha$-tubulin, acetylated $\alpha$-tubulin, or the middle-molecular-weight neurofilament protein. The antibody against $\beta$-tubulin was obtained from Amersham Corp. (Arlington Heights, IL). The general $\alpha$-tubulin antibody (that is, the antibody recognizing both acetylated and nonacetylated $\alpha$-tubulin) and the antibody specific for acetylated $\alpha$-tubulin were generously provided by Dr. Gianni Piperno (Rockefeller University, New York, NY). These antibodies are designated B-5-1-2 and 6-11B-1, respectively, and their properties are described in Piperno and Fuller (1985). The antibody against the middle-molecular-weight neurofilament protein was generously provided by Dr. Virginia Lee (Department of Neuropathology, University of Pennsylvania, Philadelphia). The properties of this antibody, designated RMO26, are described by Lee et al. (1987) and Black and Lee (1988).

The transfers were incubated with primary antibody at room temperature for 16-24 hr. The transfers were rinsed 3 times with TBS, reblocked for $15 \mathrm{~min}$, and then incubated with $10^{6} \mathrm{cpm}$ of ${ }^{25}$ I-labeled goat anti-mouse Ig (NEN, Boston) at room temperature for $2 \mathrm{hr}$. The transfers were then rinsed 5 times for 10 min each with TBS $+0.5 \%$ Triton X-100, followed by $3,1 \mathrm{hr}$ rinses in the same buffer. The transfers were then dried, spotted around their perimeter with radioactive ink, and then autoradiographed. To quantify the relative levels of antigen in the samples, the labeled bands were excised from the transfers and counted in a $\gamma$-counter (LKB Rackgamma II). The bands were located by using the radioactive ink spots on the autoradiograph and the ink spots on the blots as coordinates. Levels of background binding were assessed by counting several pieces of the transfer equal in size to the labeled bands, but not containing the antigen. Specific binding typically exceeded background by a factor of 5 or more. Results from replicate experiments are expressed as means $\pm \mathrm{SD}$.

To identify the levels of sample that result in a linear relationship between the amount of material applied to the gel and binding of ${ }^{125} \mathrm{I}$ labeled second antibody, cell extracts containing total protein ranging from 1 to $25 \mu \mathrm{g}$ were assayed as described above, and the relationship between amount of cell protein applied to the gel and ${ }^{125} I$ binding was quantified for all antibodies. In all cases, linearity was found between 1 and $10 \mu \mathrm{g}$ of cell extract, with $25 \mu \mathrm{g}$ being only slightly out of the linear range. For the experiments assaying whole-cell SDS extracts, 10 $\mu \mathrm{g}$ of total protein was applied to the gel, and samples were assayed in duplicate or triplicate.

Comparable types of analyses were also carried out on soluble and cytoskeletal preparations from control and drug-treated cultures. Because the protein content of the fractions varied with the duration of drug treatment, it was not appropriate to normalize the samples to equal protein. Instead, samples were normalized on the basis of culture equivalents. Cytoskeletal fractions from control cultures typically contain $\sim 80 \%$ of the total tubulin and $\sim 40 \%$ of the total cell protein. Between 3-6 $\mu \mathrm{g}$ of protein from the control cytoskeletal fractions was assayed. The fraction of total material represented by this amount of protein was determined, and the same fraction of the total sample from the drugtreated cultures was analyzed. For these analyses, each sample was analyzed in triplicate, and quantitation was as described above.

Gel electrophoresis. One-dimensional SDS gel electrophoresis was carried out as described previously (Peng et al., 1985). Gels consisted of 
Figure 1. Distribution of tubulin species between soluble and assembled pools. Cultures were separated into soluble and cytoskeletal fractions by extraction with Triton X-100 as described by Black et al. (1986b). The resulting fractions were resolved on 1-dimensional SDS gels and then assayed for tubulin by Coomassie Blue staining (lefthand panel) or immunoblotting (remaining panels) using antibodies against $\beta$-tubulin, $\alpha$-tubulin (both acetylated and nonacetylated), and acetylated $\alpha$-tubulin. $S$ depicts the soluble material, while $C$ depicts the cytoskeletal material. Note that while total $\alpha$ - and $\beta$-tubulin are present in both soluble and cytoskeletal fractions, acetylated $\alpha$-tubulin partitions quantitatively with the cytoskeleton.

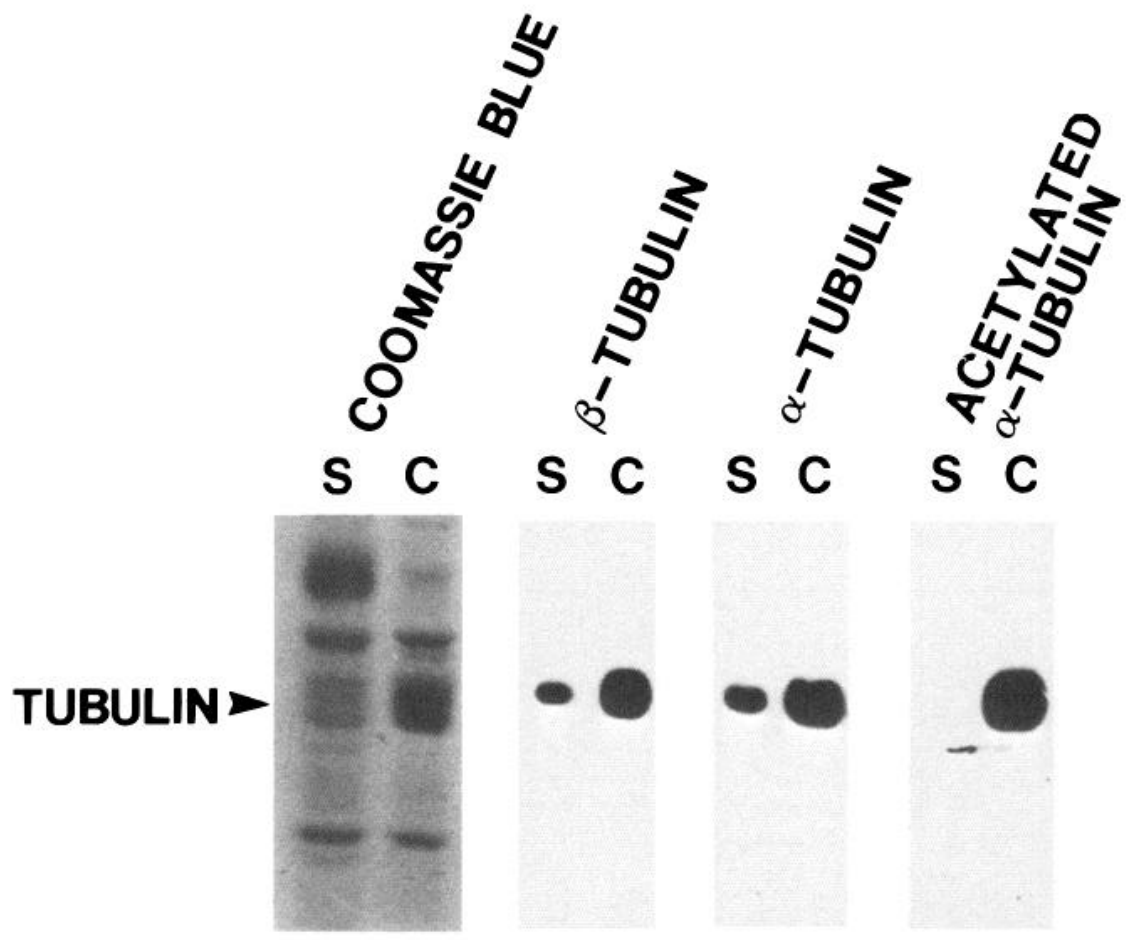

$8.5 \%$ acrylamide. Two-dimensional isoelectricfocusing $\times$ SDS-PAGE was performed as described previously (Black et al., 1984). The seconddimension gel consisted of $7.5 \%$ acrylamide and, depending on the purpose of the experiment, was based on either the Laemmli (1970) or Sheir-Neiss et al. (1978) formulations. Isoelectricfocusing slab gel electrophoresis was as described by P. W. Baas and M. M. Black (unpublished observations). For some analyses, $20 \mu \mathrm{g}$ of unlabeled brain tubulin were added to the labeled samples as carrier. Gels were stained with Coomassie Blue prior to processing for fluorography (Bonner and Laskey, 1974) or autoradiography. To quantify the amount of radioactivity associated with the proteins of interest, the bands or spots were excised from the gels, dissolved in $\mathrm{H}_{2} \mathrm{O}_{2}$, and then assayed for radioactivity by scintillation counting. Background was determined from pieces of the gel equal in size to the bands of interest but that contained no distinct bands or spots. The results are expressed as means \pm SD.

\section{Results}

Acetylated $\alpha$-tubulin is polymer specific

We have determined the distribution of various tubulin species between unassembled and assembled states using an extraction assay that quantitatively solubilizes unassembled microtubule proteins, while microtubules are stabilized and remain with the insoluble cytoskeleton. Examination of soluble and cytoskeletal fractions for $\alpha$-tubulin (both acetylated and nonacetylated) and $\beta$-tubulin by immunoblotting (Fig. 1) confirms previous quantitative analyses indicating that $75-85 \%$ of the tubulin is cytoskeletal associated (Black et al., 1986b). Quantitative analyses of a larger number of immunoblots like those of Figure 1 indicated that $83 \pm 9 \%(\bar{x} \pm \mathrm{SD}, n=5)$ of the $\alpha$-tubulin and $78 \%$ $(n=2)$ of the $\beta$-tubulin is polymerized. In contrast, similar immunoblots using the antibody specific for acetylated $\alpha$-tubulin show that $99 \pm 1 \%(n=4)$ of the acetylated tubulin is cytoskeletal associated (Fig. 1); only trace levels of acetylated $\alpha$-tubulin can be seen in the soluble fraction, and only when high levels of antigen are assayed. The low levels of acetylated $\alpha$-tubulin in the soluble fraction are not due to rapid deacetylation in vitro. When cultures are extracted in the presence of
$\mathrm{Ca}^{2+}$ to cause rapid and near total microtubule depolymerization (Black et al., 1984), acetylated $\alpha$-tubulin is seen in the soluble fraction at levels comparable to those seen in cytoskeletal fractions prepared from cultures extracted in the absence of $\mathrm{Ca}^{2+}$. These observations indicate that acetylated $\alpha$-tubulin is essentially a polymer-specific form of tubulin in cultured neurons.

Analysis of the distribution of acetylated $\alpha$-tubulin between soluble and cytoskeletal fractions using blotting assays provides information on the total mass of acetylated subunits. Newly acetylated $\alpha$-tubulin, like the total mass of acetylated subunits, is also polymer specific. Soluble and cytoskeletal fractions from cultures incubated with ${ }^{3} \mathrm{H}$-acetate for $60 \mathrm{~min}$ were assayed for acetylated subunits by SDS-PAGE and fluorography. As shown in Figure 2, the labeled subunits were detected only in the cytoskeletal fraction. The labeled subunits present in cells pulselabeled for $60 \mathrm{~min}$ and chased for $4 \mathrm{hr}$ also partitioned exclusively with the cytoskeleton. Similar results were also obtained with cultures incubated with ${ }^{3} \mathrm{H}$-acetate for $10 \mathrm{~min}$. Quantitative analyses revealed that $99.4 \pm 0.5 \%(n=4)$ of the ${ }^{3} \mathrm{H}$-labeled tubulin partitioned with the cytoskeleton. These results confirm that acetylated $\alpha$-tubulin is polymer specific.

\section{Effects of microtubule depolymerizing and stabilizing drugs on tubulin acetylation}

The absence of detectable levels of unassembled acetylated subunits suggests that tubulin polymer, rather than protomer, is the preferred substrate for acetylation. If this is correct, then incorporation of acetate into tubulin should be diminished by appropriate incubation with depolymerizing drugs but not by incubation with stabilizing drugs such as taxol. To test these predictions, cultures preincubated with either podophyllotoxin or taxol for $4 \mathrm{hr}$ were then incubated an additional $90 \mathrm{~min}$ in the drug plus ${ }^{3} \mathrm{H}$-acetate. As shown in Figure 3, preincubation with podophyllotoxin completely blocked incorporation of ace- 


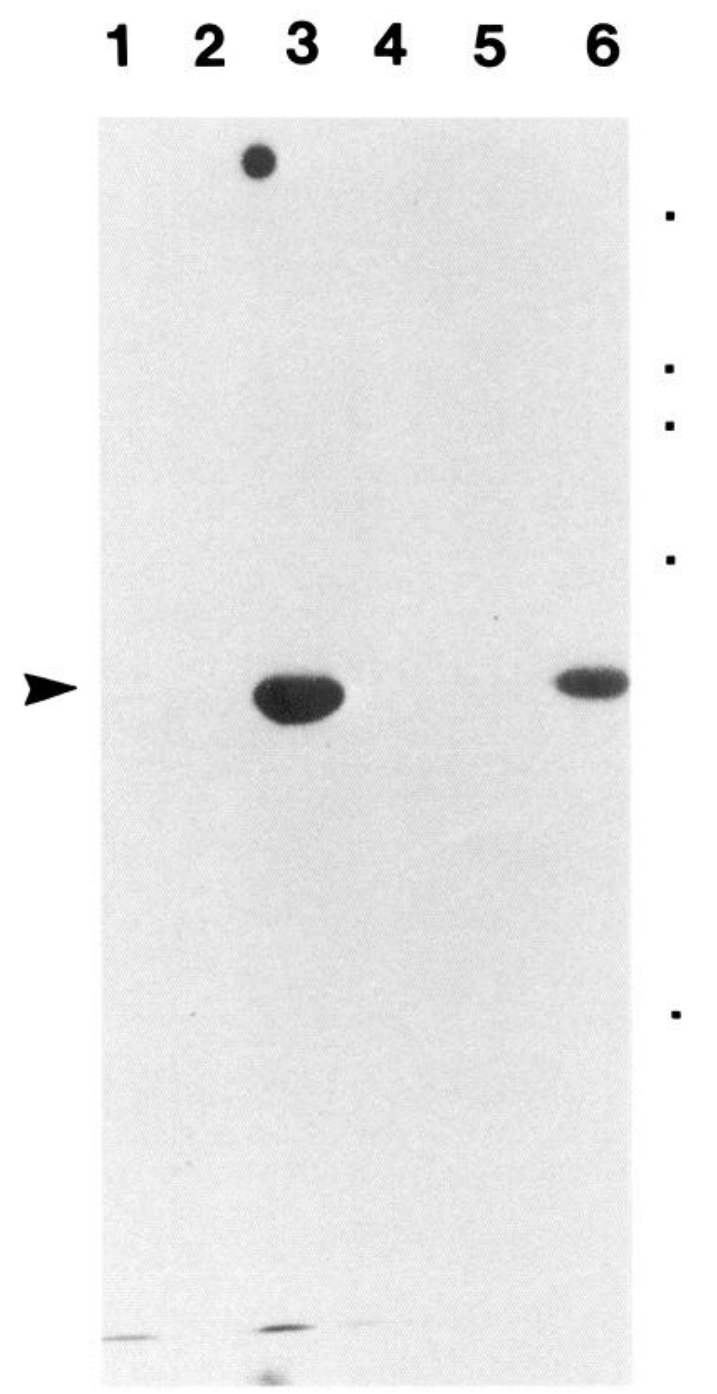

Figure 2. Partitioning of newly acetylated $\alpha$-tubulin between soluble and cytoskeletal fractions. Cultures pulse-labeled with ${ }^{3} \mathrm{H}$-acetate for 90 min and then chased for 0 or $4 \mathrm{hr}$ were separated into soluble and cytoskeletal fractions. The soluble fraction was generated by incubating the cultures for 2 successive 10 min periods in fresh microtubule-stabilizing buffer containing $0.2 \%$ Triton X-100 (see Black et al., 1986b, for further details). The 2 Triton-soluble fractions and the cytoskeletal fraction from each culture were analyzed by 1-dimensional gel electrophoresis and fluorography. Shown is a reproduction of the resulting fluorograph. Lanes 1, 2, and 3 show the labeled proteins in the 2 Tritonsoluble fractions and the cytoskeletal fraction, respectively, from the culture labeled for $90 \mathrm{~min}$ and then extracted. Lanes 4, 5, and 6 show the labeled proteins in the 2 Triton-soluble fractions and cytoskeletal fraction, respectively, from the culture labeled for $90 \mathrm{~min}$ and then chased for $4 \mathrm{hr}$. The arrowhead identifies the position of $\alpha$-tubulin in the gel. The squares to the right of the fluorograph indicate the position of molecular-weight standards, which (from top to bottom) correspond to apparent molecular weights of $200,000,116,000,94,000,68,000$, and 43,000 . With both labeling conditions, the ${ }^{3} \mathrm{H}$-labeled tubulin partitions quantitatively with the cytoskeleton.

tate into tubulin but not into a prominent nontubulin acylated protein $(\sim 200 \mathrm{kDa})$. Colchicine at $25 \mu \mathrm{M}$ and nocodazol at 4.5 $\mu \mathrm{M}$ have comparable effects on acetate incorporation into tubulin (data not shown). After $1 \mathrm{hr}$ incubations with these drugs, incorporation of acetate into tubulin is substantially diminished (by $85 \%$ in experiments with colchicine) but not completely blocked (data not shown). We note that these drugs block the

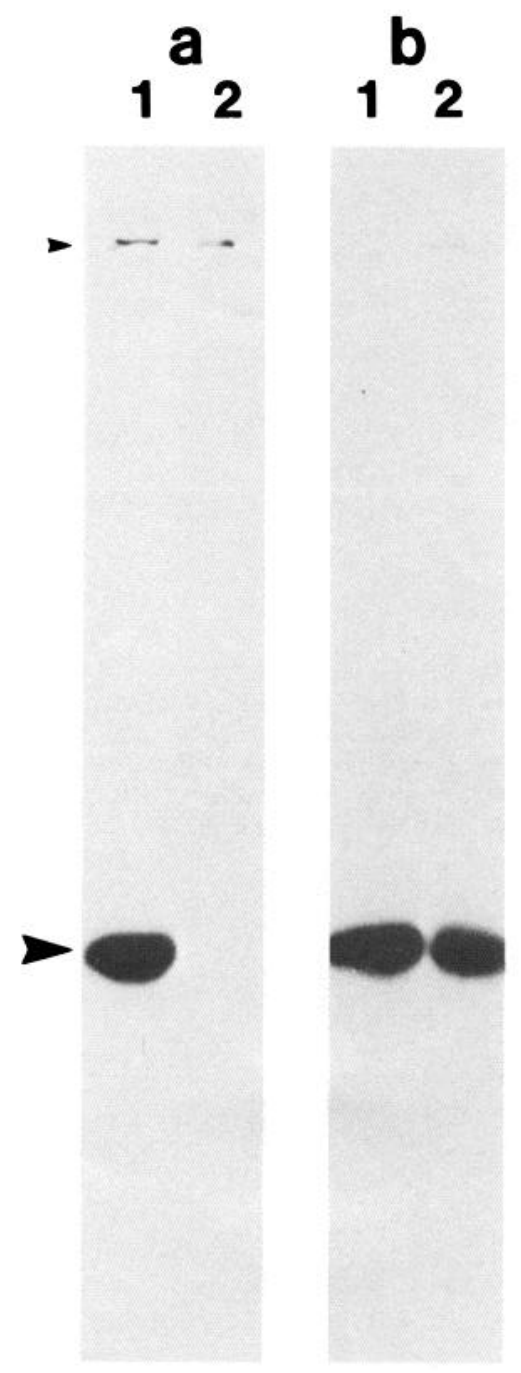

Figure 3. Effect of microtubule depolymerizing or stabilizing drugs on the incorporation of ${ }^{3} \mathrm{H}$-acetate into tubulin. Cultures were preincubated with podophyllotoxin $(4.5 \mu \mathrm{M})$, taxol $(10 \mu \mathrm{M})$, or DMSO (the solvent for the drugs) for $4 \mathrm{hr}$, and then incubated an additional $90 \mathrm{~min}$ with the indicated agent plus ${ }^{3} \mathrm{H}$-acetate. The labeled neurons were then dissolved in SDS and analyzed by 1-dimensional gel electrophoresis and fluorography. Shown are portions of the resulting fluorographs. $a$, The labeled proteins from cultures incubated with DMSO (lane 1) or podophyllotoxin (lane 2), respectively. $b$, The labeled material from cultures incubated with DMSO (lane I) or taxol (lane 2), respectively. The large arrowhead identifies the position of $\alpha$-tubulin, while the small arrowhead identifies the position of a $200 \mathrm{kDa}$ protein that is also acetylated, though to a variable extent, in neurons. Preincubation with depolymerizing drugs blocks the incorporation of acetate into tubulin, while similar incubations with taxol result in only a modest reduction in acetate incorporation into tubulin.

incorporation of acetate into tubulin without causing complete microtubule depolymerization. As shown in Figure 4, after $4 \mathrm{hr}$ of drug treatment, $\sim 50 \%$ of the polymer remains. It is unclear why little or no acetate is incorporated into these microtubules. Perhaps they are already maximally acetylated.

In contrast to the effects of microtubule-depolymerizing drugs on acetylation of tubulin, incorporation of ${ }^{3} \mathrm{H}$-acetate into tubulin is only modestly reduced following a $4 \mathrm{hr}$ preincubation of cultures with taxol under conditions sufficient to drive $\geq 98 \%$ of the tubulin into microtubules (Fig. 3). These observations 

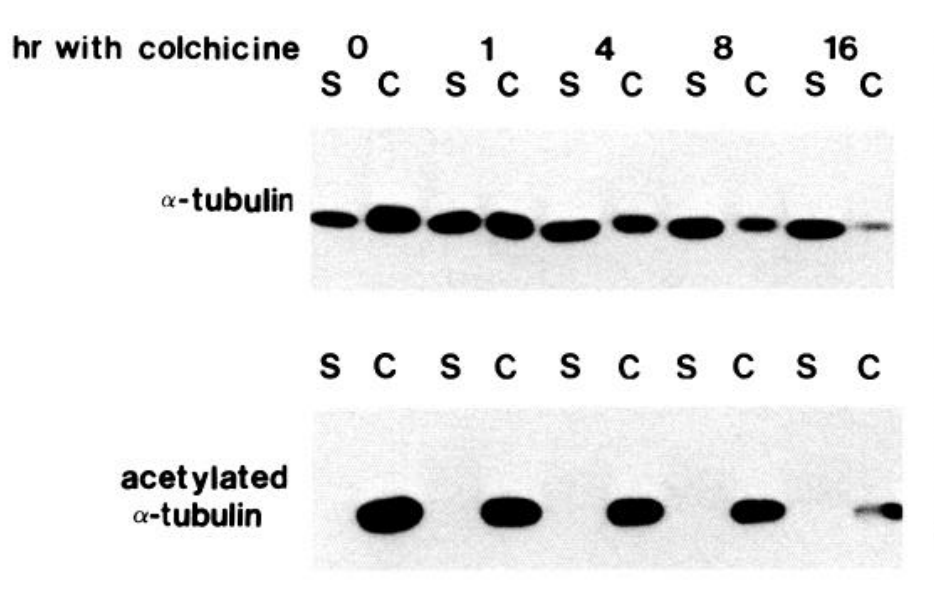

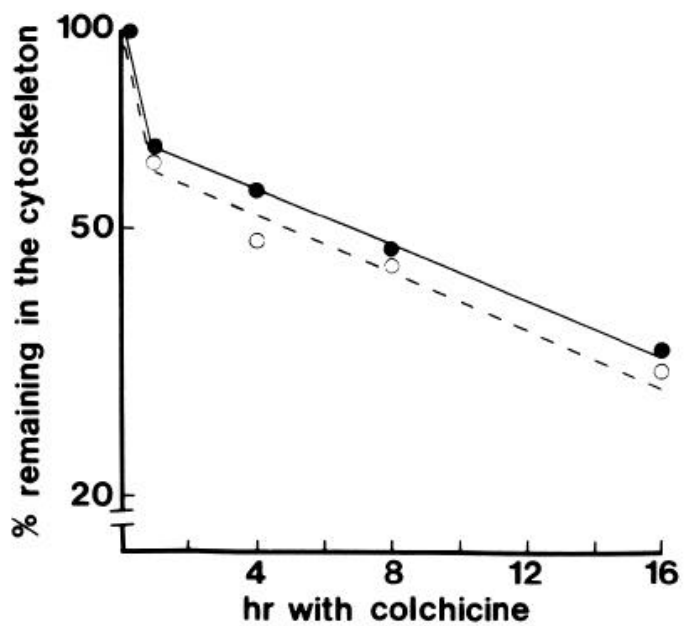

Figure 4. Effect of depolymerizing drugs on the partitioning of total $\alpha$-tubulin and acetylated $\alpha$-tubulin between soluble and cytoskeletal fractions. Cultures were incubated with $25 \mu \mathrm{M}$ colchicine for $0,1,4,8$, or $16 \mathrm{hr}$ and then separated into soluble and cytoskeletal fractions. The resulting fractions were then assayed for total $\alpha$-tubulin or acetylated $\alpha$-tubulin by immunoblotting. The 2 panels on the left depict immunoblots of the soluble $(s)$ and cytoskeletal $(c)$ fractions from the cultures probed with antibodies to total $\alpha$-tubulin or acetylated $\alpha$-tubulin. The graph shows the results of quantitative analyses on the levels of total $\alpha$-tubulin (filled circles) and acetylated $\alpha$-tubulin (open circles) in the cytoskeleton as a function of time with colchicine. The data are means of 3 separate experiments like those shown in $a$ and $b$. SDs typically ranged from 10 to $17 \%$ of the means.

indicate that tubulin polymer is an effective substrate for the acetylation reaction.

\section{Effects of depolymerizing drugs on the partitioning of acetylated and nonacetylated subunits between assembled and unassembled states}

Soluble and cytoskeletal fractions were prepared from cultures treated with colchicine, podophyllotoxin, or nocodazol for times ranging from 0 to $24 \mathrm{hr}$ and assayed for $\beta$-tubulin, total $\alpha$-tubulin (acetylated plus nonacetylated), and acetylated subunits by immunoblotting. Immunoblots obtained with antibodies to either total $\alpha$ - or $\beta$-tubulin (Fig. 4 and data not shown) reveal that treatment with colchicine leads to a gradual and progressive decrease in the levels of cytoskeletal tubulin and a concomitant increase in soluble tubulin. When soluble and cytoskeletal fractions from colchicine-treated cultures were probed for acetylated $\alpha$-tubulin, again we observed a gradual decline in the levels of acetylated tubulin in polymer that closely resembled in time course and extent the drug-induced decrease in total $\alpha$-tubulin in polymer (Fig. 4). However, we did not observe a concomitant increase in the levels of acetylated tubulin in the soluble fraction; in fact, acetylated $\alpha$-tubulin was not even detected in the soluble fraction of drug-treated cells (Fig. 4). Qualitatively comparable findings were also obtained with podophyllotoxin and nocodazol (data not shown). We interpret these findings to indicate that acetylated $\alpha$-tubulin is deacetylated sufficiently rapidly upon depolymerization that it fails to accumulate in an unassembled form. One alternative, namely, that acetylated $\alpha$-tubulin is degraded upon depolymerization, is unlikely because total levels of $\alpha$-tubulin, as probed by an antibody that recognizes both acetylated and nonacetylated forms of $\alpha$-tubulin, remain unchanged throughout the period of drug treatment (Fig. 5).

\section{Deacetylation of tubulin in situ}

The previous observations indicate that acetylated tubulin is polymer specific and that deacetylation is coupled to depolymerization. Thus, the rate at which acetate is lost from tubulin in situ should approximate the average rate at which tubulin subunits cycle off acetylated microtubules. Two approaches have been used to determine the kinetics of deacetylation of $\alpha$-tubulin in intact neurons. In one, the rate of loss of acetylated subunits from neurons treated with depolymerizing drugs was quantified. In the second, pulse-chase protocols were used to quantify the turnover of newly incorporated acetate on tubulin. As will be seen below, similar results were obtained with both approaches.

\section{Effects of depolymerizing drugs on the levels of acetylated subunits in neurons}

Cultures treated with colchicine for times ranging from 0 to 23 $\mathrm{hr}$ were assayed for levels of total $\beta$-tubulin, total $\alpha$-tubulin, and acetylated $\alpha$-tubulin by quantitative immunoblotting as described in Materials and Methods. In addition, the effects of colchicine treatment on the levels of the middle-molecular-weight neurofilament subunit (NF-M) was also quantified because we felt that drug treatment would have little or no effect on its levels under the conditions of the present experiments.

Treatment with colchicine had no detectable effect on the levels of total tubulin or NF-M (Fig. 5). In contrast, the levels of acetylated $\alpha$-tubulin decreased progressively with time in drug, and this decrease exhibited biphasic kinetics (Fig. 5). Approximately $30 \%$ of the acetylated subunits decreased with a $t_{n / 2}$ of $\sim 2 \mathrm{hr}$ in the presence of colchicine, whereas the remaining acetylated subunits decreased with a $t_{1 / 2}$ of $\sim 10 \mathrm{hr}$. Very similar results were obtained for acetylated $\alpha$-tubulin when cytoskeletons instead of whole-cell extracts were analyzed (compare Figs. 5 and 4). This close similarity is, in fact, expected because acetylated tubulin is polymer specific and is rapidly deacetylated following depolymerization. When podophyllotoxin was used instead of colchicine, $\sim 30 \%$ of the acetylated subunits decreased with a $t_{1 / 2}$ of $\sim 2 \mathrm{hr}$, whereas the remaining $70 \%$ decreased with a $t_{1 / 2}$ of $\sim 7 \mathrm{hr}(n=2$, data not shown). Because the levels of total $\alpha$-tubulin remain unchanged during treatment with these drugs (Fig. 5), the drug-induced decrease in levels of acetylated $\alpha$-tubulin must reflect its conversion to nonacetylated subunits. 


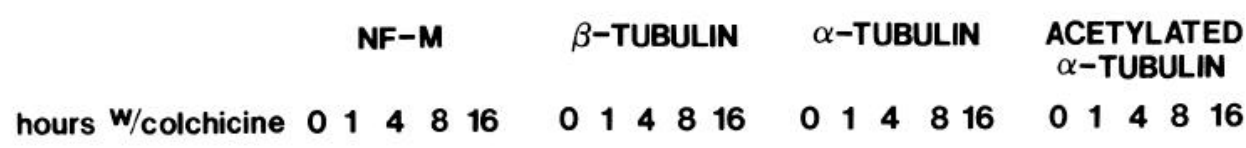

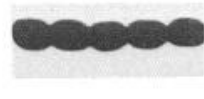
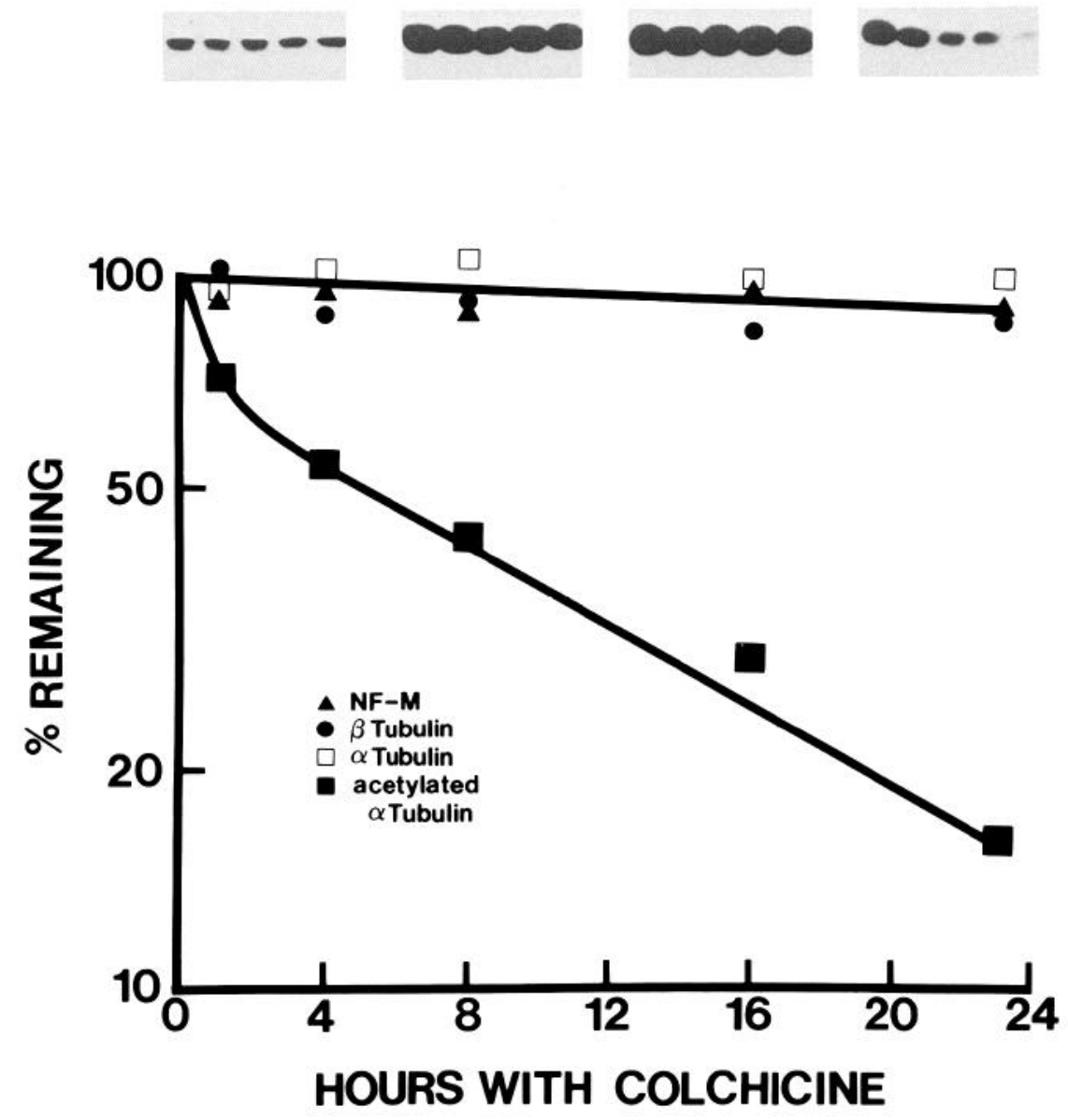

Figure 5. Effects of colchicine on the total levels of various tubulin species and on the middle-molecular-weight neurofilament subunit (NF-M) in cultured neurons. Cultures were incubated with $25 \mu \mathrm{M}$ colchicine for the indicated times (in hours) and then assayed for NF-M, $\beta$-tubulin, total $\alpha$-tubulin, and acetylated $\alpha$-tubulin by immunoblotting. Upper panel, Representative immunoblots; lower panel, quantitative data from 3 separate experiments like those depicted above. The symbols (defined in the figure) represent means of the 3 experiments (except for the $23 \mathrm{hr}$ point, which is from 1 experiment). SDs typically ranged from 10 to $15 \%$ of the mean. Note that while the levels of NF-M and total $\alpha$-tubulin and $\beta$-tubulin remain unchanged during drug treatment, the levels of acetylated $\alpha$-tubulin decrease biphasically as a function of time in drug.

Because this conversion is closely coupled to depolymerization (see above), we suggest that 2 populations of acetylated microtubules can be distinguished in cultured neurons based on their sensitivity to depolymerizing drugs, one that depolymerizes with a $t_{1 / 2}$ of $\sim 2 \mathrm{hr}$ and the other that depolymerizes with a $t_{1 / 2}$ of 7$10 \mathrm{hr}$, depending on the drug used.

\section{Turnover of newly incorporated acetate on tubulin}

Sister cultures were pulse-labeled with ${ }^{3} \mathrm{H}$-acetate for $90 \mathrm{~min}$ and then chased in the absence of label for times ranging from 0 to $23 \mathrm{hr}$. Previous studies have established that the labeled tubulin generated with such labeling conditions is due largely to the posttranslational incorporation of acetate into tubulin (see Black and Keyser, 1987, for details and further discussion). General protein labeling due to the metabolic conversion of radioactive acetate to amino acids followed by their incorporation into protein is negligible. As a measure of the specificity of the labeling of $\alpha$-tubulin, samples incubated with ${ }^{3} \mathrm{H}$-acetate for $90 \mathrm{~min}$ were analyzed by 2 -dimensional PAGE, and the radioactivity associated with $\alpha$-tubulin and $\beta$-tubulin was quantified. Under these conditions, the ratio of labeling of $\alpha$-tubulin to $\beta$-tubulin was $27 \pm 3(n=3)$. This contrasts with the ratio expected for incorporation of amino acids into tubulin, which is $\sim 1$. Thus, under the conditions of our experiments, labeling of $\alpha$-tubulin by means other than posttranslational acetylation is negligible.

Figure 6 shows a fluorographic exposure depicting the relative levels of ${ }^{3} \mathrm{H}$-acetate-labeled $\alpha$-tubulin as a function of the chase time, as well as the quantitative data from a larger number of similar experiments. Newly incorporated acetate is lost from tubulin with biphasic kinetics: $\sim 55 \%$ of the label is lost with a $t_{1 / 2}$ of $\sim 1.4 \mathrm{hr}$, with the remaining label decaying with a $t_{1 / 2}$ of 4.5-5 hr. We interpret these turnover data as indicating the existence of 2 distinct pools of acetylated microtubules that can be distinguished by their rates of subunit turnover (see Discussion).

These pulse-chase analyses provide information on the acetylated subunits that become labeled during incubation with ${ }^{3} \mathrm{H}$ acetate. Because these labeled subunits represent only a portion of the total acetylated subunits, the relative levels of the 2 pools of labeled acetylated subunits may not be indicative of those at steady state. If this is correct, then by increasing the labeling time, the proportion of labeled acetylated microtubules with the slower or faster half-times should approach the steady state. Attempts to directly test this prediction were unsuccessful because substantial conversion of ${ }^{3} \mathrm{H}$-acetate to radiolabeled amino acids occurred with long ( $\sim 16 \mathrm{hr}$ ) labeling times, and these amino acids were then incorporated into tubulin by normal protein synthetic mechanisms. 

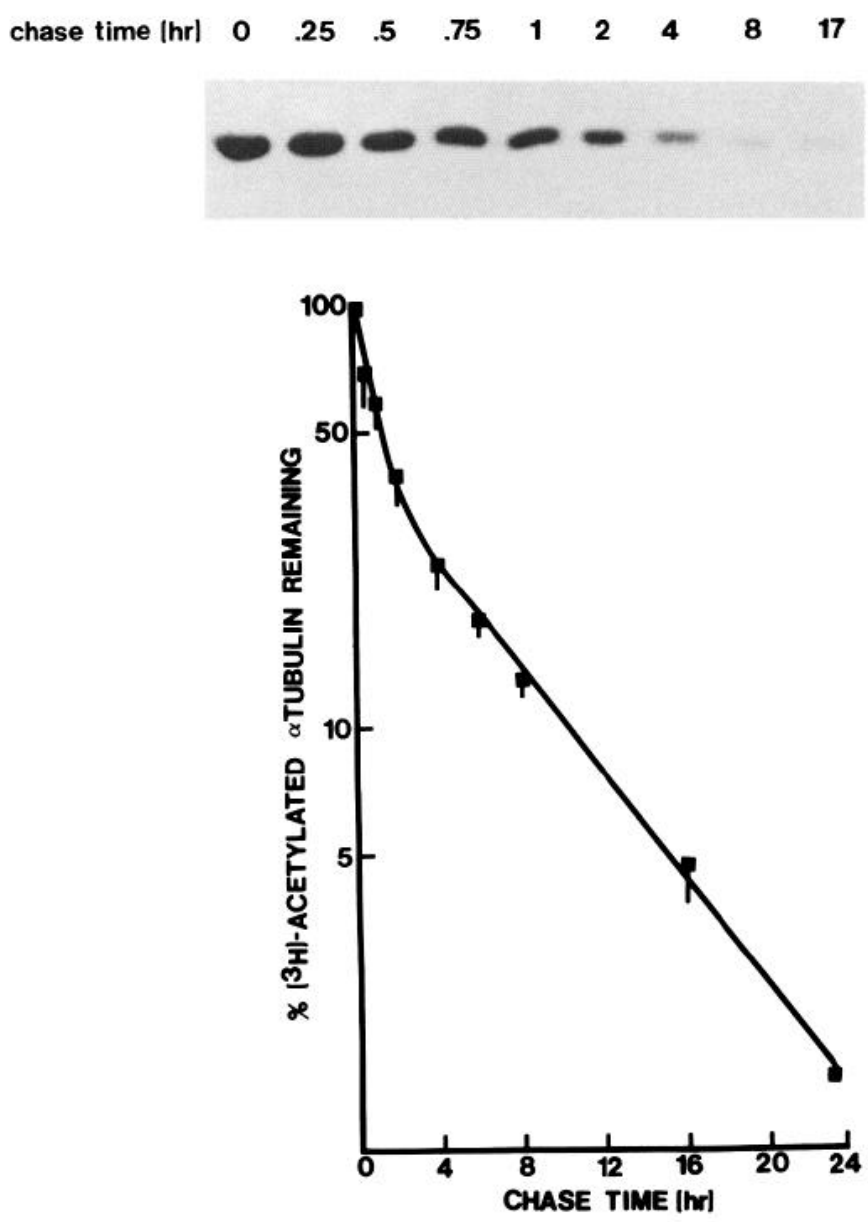

Figure 6. Turnover of newly incorporated acetate on tubulin. Cultures were pulse-labeled with ${ }^{3} \mathrm{H}$-acetate for $90 \mathrm{~min}$ and then chased in the absence of label for times ranging from 0 to $23 \mathrm{hr}$. The labeled neurons were dissolved in SDS and then assayed for levels of ${ }^{3} \mathrm{H}$-labeled tubulin by 1-dimensional gel electrophoresis and fluorography. Upper panel, The tubulin-containing region from a representative fluorograph, with the chase times (in hours) indicated above the various lanes; lower panel, the quantitative data from a larger number of similar experiments. The data presented are means \pm SD from 4 replicate experiments, except the $23 \mathrm{hr}$ point, which is based on 1 experiment. See text for additional discussion.

The turnover kinetics of acetate on tubulin bear no resemblence to the turnover of the protein itself. Pulse-chase analyses of tubulin turnover during a $20 \mathrm{hr}$ period (see Materials and Methods) revealed that very little turnover of tubulin occurred: $86 \pm 18 \%(n=4)$ of the initial counts in tubulin remained after $20 \mathrm{hr}$. Assuming that the turnover can be described by a single exponential, then these data indicate a $t_{1 / 2}$ of $\sim 72 \mathrm{hr}$ for tubulin in cultured sympathetic neurons.

\section{Taxol and azide block the turnover of acetate on tubulin}

If, as we have argued above, the loss of acetate from tubulin is coupled to its depolymerization, then we should be able to accelerate or decrease the rate of acetate turnover with drugs that either depolymerize or stabilize, respectively, tubulin polymer. We have tested this prediction by examining acetate turnover in cultures labeled with ${ }^{3} \mathrm{H}$-acetate for $1-2 \mathrm{hr}$ and then chased for varying times in the presence of either microtubule depolymerizing drugs or taxol. Microtubule depolymerizing drugs appeared to increase acetate turnover only slightly (Fig. 7a). This minimal effect presumably reflects the fact that the time course of microtubule depolymerization in the presence of these drugs is quite slow relative to that of acetate turnover. In contrast, including taxol in the chase medium greatly slowed the turnover of newly incorporated acetate (Fig. 7a). After a $1 \mathrm{hr}$ chase in the presence of taxol, the level of radioactivity in $\alpha$-tubulin was somewhat greater than at the end of the pulse period, and this level decreased very slowly over the subsequent $23 \mathrm{hr}$. We have shown previously that the conditions of taxol treatment used here drive $\geq 98 \%$ of the tubulin into microtubules (Black, 1987). Thus, when the stability of the microtubules is pharmacologically enhanced by treatment with taxol, acetate turnover is diminished. This may indicate that microtubules are not effective substrates for the deacylase. Alternatively, taxol binding to the microtubules may sterically (or otherwise) hinder the deacylase (Thompson et al., 1984).

To better understand the results with taxol, we have examined the effect of another microtubule stabilizing agent on the turnover of newly incorporated acetate on tubulin. These experiments used azide. In other systems, azide stabilizes microtubules indirectly by reducing cellular ATP and thereby interferes with the depolymerization reaction (Bershadsky and Gelfand, 1981). In control experiments, we established that the same is apparently true for neurons; treatment of neurons with $20 \mathrm{~mm}$ azide in the absence of glucose reduced the extent of colchicine-induced microtubule depolymerization compared with control cells (data not shown). As shown in Figure $7 b$, including $20 \mathrm{~mm}$ azide in the chase medium substantially slows the turnover of newly incorporated acetate on tubulin. The deacylase does not require ATP (Maruta et al., 1986), but microtubule depolymerization apparently does. Thus, by depleting cellular ATP, microtubules are stabilized and acetate turnover is slowed. On the basis of these results and those with taxol, we conclude that microtubules are not effective substrates for the deacylase in situ.

\section{Isoform composition of acetylated $\alpha$-tubulin}

Several electrophoretically distinct forms of $\alpha$-tubulin exist in brain (Field and Lee, 1985), and the same is true for cultured neurons (Gozes and Sweadner, 1981). Several of these variants are acetylated in situ (P. W. Baas and M. M. Black, unpublished observations). We have tested the possibility that the variants comprising the slowly turning over population of acetylated subunits represent a subset of the total acetylated isoforms. Cultures pulse-labeled with ${ }^{3} \mathrm{H}$-acetate for $90 \mathrm{~min}$ and then chased for 0 or $8 \mathrm{hr}$ were assayed for acetylated tubulin isoform composition by isoelectricfocusing slab gel electrophoresis. The sample from the culture chased for $8 \mathrm{hr}$ is largely depleted of the rapidly turning over acetylated $\alpha$-tubulin subunits and thus contains predominantly the more slowly turning over acetylated subunits. The profile of labeled acetylated $\alpha$-tubulin variants was quite similar in both samples. We conclude that the same variants of $\alpha$-tubulin comprise the rapidly and slowly turning over populations of acetylated subunits; there was no clear evidence for specific acetylated variants associated with one or the other of these acetylated tubulin pools.

\section{Discussion}

The available information on the acetylation and deacetylation of $\alpha$-tubulin in intact cells suggests that acetylation occurs postpolymerization, whereas deacetylation is temporally coupled to depolymerization. This scheme parallels that recently described 


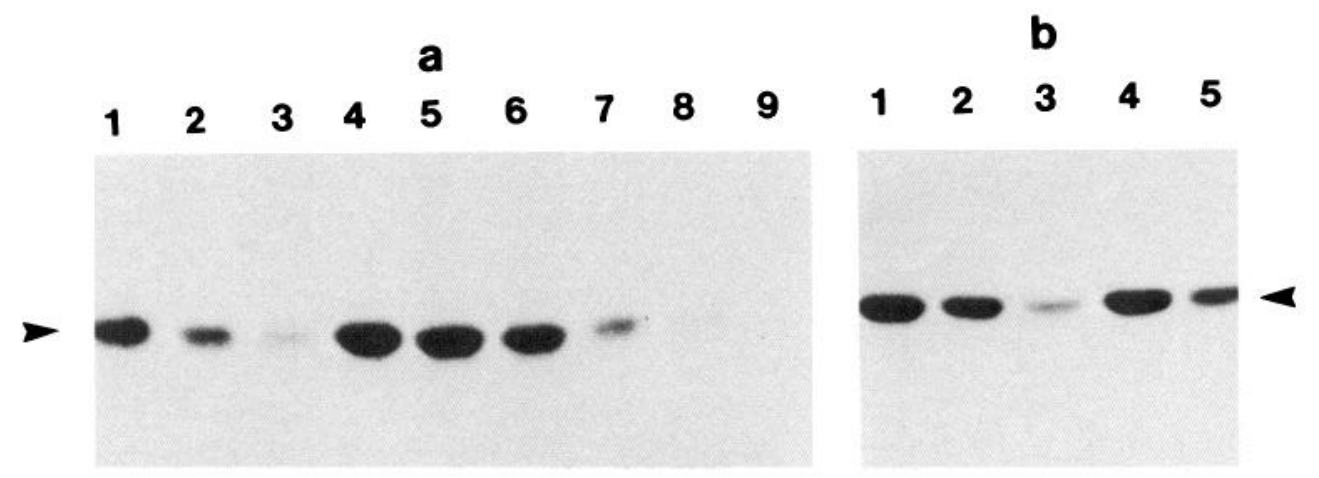

Figure 7. Effect of taxol, podophyllotoxin, and azide on the turnover of newly incorporated acetate on tubulin. $a$, Cultures were incubated with ${ }^{3} \mathrm{H}$-acetate for $90 \mathrm{~min}$ and then chased for varying times thereafter in the presence of $10 \mu \mathrm{M}$ taxol, $4.5 \mu \mathrm{M}$ podophyllotoxin, or no addition. The neurons were then scraped into SDS and assayed for ${ }^{3} \mathrm{H}$-labeled tubulin by 1-dimensional gel electrophoresis and fluorography. Shown is a portion of a fluorograph from 1 of 3 replicate experiments. Lane 1, no chase; lanes 2 and 3,1 and $4 \mathrm{hr}$ chase periods, respectively, with no additions; lanes 4,5 , and $6,1,4$, and $23 \mathrm{hr}$ chase periods, respectively, in the presence of taxol; lanes 7, 8, and 9, 1, 4, and $23 \mathrm{hr}$ chase periods, respectively, in the presence of podophyllotoxin. Lane 1 is the zero chase for the control as well as taxol- and podophyllotoxin-treated cultures. $b$, Cultures were labeled as described for $a$, and then chased for 0,1 , or $4 \mathrm{hr}$ with no additions (lanes 1,2 , and 3 , respectively) or in the presence of 20 mu azide for 1 or $4 \mathrm{hr}$ (lanes 4 and 5 , respectively). Lane 1 is the zero chase for the control and azide-treated cultures. For these experiments, the chase medium consisted of BSS supplemented with the serum and hormonal supplements used for the standard feed medium (see Materials and Methods). Taxol and azide, which stabilize microtubules, slow the turnover of newly incorporated acetate on tubulin, while podophyllotoxin appears to slightly accelerate acetate turnover.

for the cyclic detyrosination/tyrosination of $\alpha$-tubulin in tissue culture cells (Gunderson et al., 1987).

\section{$\alpha$-Tubulin acetylation occurs postpolymerization}

Initial indications that acetylation occurs postpolymerization stem from studies with Chlamydomonas flagella, which show that acetylated $\alpha$-tubulin is associated specifically with axonemal microtubules, and not with the flagellar matrix, which contains unassembled tubulin (L'Hernault and Rosenbaum, 1983; Piperno and Fuller, 1985). These indications were then reinforced by the observations that during microtubule regrowth following drug-induced depolymerization, the appearance of acetylated microtubules lagged significantly behind the reformation of a normal-appearing microtubule complex (Piperno et al., 1987) and that depolymerizing drugs inhibit $\alpha$-tubulin acetylation in Chlamydomonas (L'Hernault and Rosenbaum, 1983).

The present studies provide several indications that acetylation occurs postpolymerization in cultured neurons as well. First, relatively short $(\leq 4 \mathrm{hr})$ treatments of cultured neurons with taxol under conditions that drive $\geq 98 \%$ of the tubulin into polymer have little effect on the incorporation of acetate into tubulin (Fig. 3), indicating that tubulin polymer is an effective substrate for the tubulin acetyltransferase in situ. Tubulin polymer is also an effective substrate for the enzyme under in vitro conditions, in which it is also a better substrate than tubulin protomer (Maruta et al., 1986). Second, $\geq 99 \%$ of the total mass of acetylated tubulin partitions with microtubules in extraction assays which separate soluble from polymeric tubulin (Fig. 1). The same is also true for newly acetylated $\alpha$-tubulin (Fig. 2). It is uncertain whether the low levels of soluble acetylated subunits observed actually exist within the cell or were generated artifactually during extraction. In any event, it is clear that they represent $\leq 1 \%$ of the total acetylated subunits. Finally, treatment of neurons with microtubule depolymerizing drugs blocks the incorporation of acetate into tubulin (Fig. 3), even though the levels of soluble unacetylated subunits are increased considerably over control levels (Fig. 4). These findings indicate that polymer is the preferred substrate in neurons and that acetylation of unassembled subunits is at best a minor pathway. The alternative explanation that soluble subunits are acetylated and that these modified subunits are preferentially assembled is unlikely in view of the in vitro data showing that the assembly properties of acetylated $\alpha$-tubulin are indistinguishable from those of nonacetylated subunits (Maruta et al., 1986).

In the preceding discussion, we have argued that acetylation occurs postpolymerization and have not mentioned the possibility that the modification is coupled to polymerization. The following considerations suggest that coupling of acetylation to polymerization does not occur. Pulse-chase analyses demonstrate that newly synthesized tubulin becomes detectably acetylated between 4-6 hr after its synthesis (Black and Kurdyla, 1983). In contrast, tubulin is synthesized as a soluble precursor that is rapidly assembled into microtubules, reaching steadystate levels of assembly within $\sim 2 \mathrm{hr}$ of its synthesis. This newly assembled $\alpha$-tubulin has the electrophoretic properties expected for the unacetylated subunit (Black et al., 1986b). These results indicate that initial acetylation of tubulin is not coupled to initial polymerization in any direct manner. Similarly, in non-neuronal cells recovering from depolymerizing drugs, reappearance of acetylated microtubules is most consistent with the acetylation of preexisting microtubules rather than a coupled assembly and acetylation mechanism (Piperno et al., 1987).

\section{Deacetylation of acetylated $\alpha$-tubulin is closely coupled to depolymerization}

The evidence that deacetylation is temporally coupled to depolymerization stems from analyses of the effects of microtubule depolymerizing drugs on the levels of total tubulin and acetylated tubulin in polymer and protomer. Treatment of cultured neurons with such drugs results in a gradual and progressive decrease in the levels of total tubulin in polymer and a corresponding increase in the levels of soluble subunits (Fig. 4). Such treatments also cause a progressive decrease in the levels of acetylated subunits in polymer that closely parallels in time course and extent the decrease in total polymer (Fig. 4). How- 
ever, there is no corresponding increase in the levels of soluble acetylated subunits. Because the total level of $\alpha$-tubulin remains unchanged during drug treatment (Fig. 5), the decrease in acetylated subunits is due to their conversion to nonacetylated $\alpha$-tubulin, and not to degradation. Thus, during drug-induced depolymerization of acetylated microtubules, acetylated subunits are converted to nonacetylated subunits sufficiently rapidly that they fail to accumulate in soluble form. The precise relationship between depolymerization and deacetylation is unclear. We favor the hypothesis that acetylated subunits come off the microtubule and are then rapidly deacetylated because agents that stabilize microtubules either directly or indirectly, such as taxol or azide, respectively, block or diminish deacetylation (Fig. 7). These results suggest that depolymerization is, in effect, rate limiting, and perhaps obligatory, for deacetylation in situ.

\section{Microtubule dynamics in neurons}

Our findings on $\alpha$-tubulin deacetylation suggest that the turnover of acetate on tubulin can be used as an indirect measure of subunit turnover for acetylated microtubules. The basic assumption underlying this strategy is that the rate of turnover of acetate on tubulin is a useful approximation of the rate at which subunits cycle off acetylated microtubules. The close similarity in the time course of tubulin deacetylation and microtubule depolymerization (see above) indicates that this assumption is reasonable. Pulse-chase protocols were used to quantify acetate turnover in untreated neurons. Because the mass of microtubules remains more or less constant in these experiments, the loss of subunits from microtubules is balanced by the addition of subunits onto microtubules. Therefore, estimates of the rates at which subunits come off acctylated microtubules should be indicative of the rates of subunit exchange or turnover. We observed that $\sim 55 \%$ of the acetate on tubulin turned over with a $t_{1 / 2}$ of $\sim 1.5 \mathrm{hr}$, while the remaining $\sim 45 \%$ turned over with a $t_{1 / 2}$ of $\sim 5 \mathrm{hr}$ (Fig. 6). We suggest that these kinetically distinguishable pools of acetylated $\alpha$-tubulin reflect distinct pools of acetylated microtubules that differ in their average rates of subunit turnover; approximately hall of the acetylated microtubules turn over with a $t_{1 / 2}$ of $\sim 1.5 \mathrm{hr}$, whereas the other half turns over with a $t_{1 / 2}$ of $\sim 5 \mathrm{hr}$. Because the majority of $\alpha$-tubulin in cultured neurons is acetylated (Black and Keyser, 1987), and acetylated $\alpha$-tubulin is polymer specific, we conclude that the rates of subunit turnover for acetylated microtubules inferred from the acetate turnover analyses are representative of the majority of microtubules (or most of the polymer mass) in these neurons. These half-lives are based on analyses of populations of microtubules in intact neurons and thus should be viewed as averages for these populations; the specific behavior of individual microtubules may vary from these values (Mitchison and Kirschner, 1984; Rothwell et al., 1987).

We have used a second method to study microtubule turnover in intact neurons in an attempt to obtain independent support for the results derived from the acetate turnover analyses. These studies quantified the rates of microtubule depolymerization under drug-induced conditions of net microtubule depolymerization. The findings are very similar to those obtained with unperturbed neurons. Subunit loss from total as well as from acetylated microtubules in drug-treated neurons occurs biphasically, and the half-lives of the slower and faster turning over material, 7-10 and $2 \mathrm{hr}$, respectively, are reasonably close to those derived from the acetate turnover studies. Even the relative amounts of acetylated microtubules that turn over with the faster versus slower time course in drug-treated or unperturbed neurons are in the same range. In drug-treated neurons, $70 \%$ of the microtubules turn over at the slower rate and $30 \%$ turn over at the faster rate, while in unperturbed neurons, the values are $\sim 50 \%$ for each. The small differences between these values may result from technical differences in the methods used to assay acetylated tubulin rather than from fundamental differences in subunit loss from microtubules in normal versus drug-treated neurons. In particular, the levels of acetylated microtubules in drug-treated neurons were assayed by blotting, which measures the total quantity of subunits in both the slower and faster turning over polymers. The turnover of acetylated microtubules in unperturbed neurons was studied with pulsechase protocols, which provide information only on those subunits that become labcled during the pulse period. As these are likely to represent a small fraction of the total acetylated subunits in microtubules, the relative levels of labeled subunits in the slower or faster turning over material may not be representative of those at steady state. If this is correct, then the distribution of acetylated subunits between the slower or faster turning over microtubules may be better approximated by the drug experiments.

It is significant that the results obtained with the 2 methods are so similar. Each method has its own limitations. For example, the drug experiments are limited by the complexity of drug action coupled with an imperfect understanding of this complexity, while the analyses of acetate turnover are indirect. Because of these limitations and others mentioned above, the values for microtubule turnover obtained with either method must be viewed as approximations. Nonetheless, the close similarity in the results obtained with these 2 independent approaches reinforces the view that they approximate the true values for subunit turnover in microtubules in intact cultured neurons reasonably well.

The kinetically distinct pools of acetylated microtubules defined by the present studies may reflect distinct populations of microtubules or distinct domains on individual microtubules. The basis for the differences in relative stability of these 2 pools is presently unknown. However, it seems unlikely that it is due to acetylation per se because both pools are acetylated and are composed of the same population of acetylated variants.

\section{Microtubule dynamics in neuronal versus non-neuronal cells}

It is instructive to compare the present results on microtubule dynamics in neurons with the available information in other cells. Microtubule dynamics has generally been defined in 2 ways. Most analyses have relied on the relative sensitivity of microtubules to depolymerization induced by various drugs, low temperature, or dilution; labile or dynamic microtubules rapidly depolymerize when subjected to these treatments, while stable microtubules do not (Behnke and Forer, 1967; Piperno et al., 1987). This stability is not absolute because in most cases stable microtubules do depolymerize but much more slowly than labile microtubules. More recently, methods have been developed to define microtubule stability in terms of the rate of subunit turnover; labile or dynamic microtubules turn over with a $t_{1 / 2}$ of 5 $20 \mathrm{~min}$, while stable microtubules have been operationally defined as turning over with a $t_{1 / 2}$ of 1 or more hours (Schulze and Kirschner, 1986, 1987; Webster et al., 1987, 1988). These 2 approaches appear to define similar populations of microtubules.

In the fibroblastic cells commonly used to study microtubule 
dynamics in situ, the majority of microtubules are labile or dynamic, having half-lives of only a few minutes; stable microtubules make up a very small percentage of the total polymer mass (Schulze and Kirschner, 1987; Webster et al., 1988). The present results indicate that the microtubule complex of cultured neurons consists predominantly of relatively stable microtubules, and this is true when stability is defined on the basis of drug sensitivity or subunit turnover. For example, in the presence of depolymerizing drugs, all microtubules depolymerize with a $t_{1 / 2} \geq 2 \mathrm{hr}$, and of these, $\sim 70 \%$ depolymerize with a $t_{1 / 2}$ of 7-10 hr. These times are much longer than those characterizing labile microtubules, which largely depolymerize within 1$2 \mathrm{hr}$ of drug treatment. In unperturbed neurons the majority of microtubules exchange subunits with a $t_{1 / 2} \geq 1.5 \mathrm{hr}$, and of these, half or more have a $t_{1 / 2}$ of $\sim 5 \mathrm{hr}$. Studies with other neuronal systems also indicate that a relatively high portion of the microtubule mass is stable based on its relative insensitivity to various depolymerization-promoting conditions (Black and Greene, 1982; Morris and Lasek, 1982; Brady et al., 1984). Collectively, these results indicate that the microtubule framework of neurons is characterized by a predominance of relatively stable microtubules.

\section{Stable microtubules and neuronal shape}

What is the significance of the preponderance of relatively stable microtubules in neurons? Neurons express a relatively stable and highly polarized morphology that is an essential feature of their function. The elaboration and maintenance of this specialized morphology presumably involves the generation and stabilization of particular arrangements of the architectural elements of the neuron. Microtubules arc prominent architectural elements in neurons. They provide the principal structural support for newly formed neurites, and they are major determinants of the caliber of most dendrites and axons (reviewed by Stevens et al., 1988). Caliber has a direct influence on the cable properties of these neurites and, thereby, on how they transmit information (reviewed by Rall and Segev, 1988). Thus, microtubules contribute to functionally important aspects of neuron shape. The predominance of stable microtubules in neurons may reflect specializations that help generate and maintain the highly polarized morphology that is so crucial to neuron function.

This notion is supported by the results of studies showing that the stability of neuronal morphology and of neuronal microtubules are coordinately regulated during development. The most detailed information stems from studies with the neuronlike PC12 model system, which can be induced to extend neurites by treatment with NGF (Greene and Tischler, 1976). In cultures of PC12 cells, as well as of neurons, early neurite outgrowth is characterized by the initiation, elongation, and then retraction of neurites (Jacobs and Stevens, 1987). Eventually, the behavior of the cell stabilizes so that specific neurites persist and continue to elongate. These persistent neurites become the axonal and dendritic neurites of the mature neuron. The relative stability of neuronal microtubules also changes during neurite outgrowth. Prior to and during the early phase of neurite outgrowth, microtubules of PC 12 cells are readily depolymerized by standard microtubule-depolymerizing agents such as colchicine and low temperature. However, as time in NGF increases and neurite outgrowth proceeds, the microtubules become relatively resistant to these treatments (Black and Greene, 1982; Jacobs and Stevens, 1986b). This enhanced stability to depolymerizing agents is accompanied by an increase in the relative levels of tubulin in polymer (Drubin et al., 1985; Black et al., 1986a) and by an increase in the average length of microtubules (Jacobs and Stevens, 1986a). These longer and more stable microtubules are concentrated in the neurites (Black and Greene, 1982; Jacobs and Stevens, 1986a) and, as shown in PC12 cells (Black and Greene, 1982) and in neurons (the present studies), comprise the majority of the polymer mass. This increase in microtubule stability occurs in concert with the stabilization of neurite morphology. It seems unlikely that the apparent coordination of the changes in morphologic stability and microtubule stability is merely coincidental. Rather, we suggest that the stabilization of neuronal microtubules is one of the key cellular events in the generation of mature neuronal morphology.

The shapes of neurons show remarkable stability. The basic morphology established during development persists throughout the life of the neuron, a time period typically measured in years. However, the neuron also exhibits considerable morphological plasticity throughout its life. In particular, recent studies emphasize that aspects of dendritic shape are quite dynamic in the normal adult (Purves and Hadley, 1985). This flexibility permits the neuron to modify its form and thereby its function in response to environmental signals. The ability of the neuron to maintain a particular shape, as well as to adjust aspects of its shape to changing environmental signals, indicates a corresponding flexibility in the arrangement of the architectural elements that determine neuron shape. The present discussion has emphasized how the unusual stability of neuronal microtubules may be a specialization involved in the maintenance of neuron shape. Future studies on the dynamic properties of microtubules and other cytoskeletal elements within the neuron will ultimately definc how the propertics of plasticity and stability are balanced in the cytoskeleton to provide for the flexibility as well as the stability that characterizes neuronal morphology.

\section{References}

Behnke, O., and A. Forer (1967) Evidence for four classes of microtubules in individual cells. J. Cell Sci. 2: 169-192.

Bershadsky, A. D., and V. I. Gelfand (1981) ATP-dependent regulation of cytoplasmic microtubule disassembly. Proc. Natl. Acad. Sci. USA $78: 3610-3613$.

Black, M. M. (1987) Taxol interferes with the interaction of microtubule-associated proteins with microtubules in cultured neurons. J. Neurosci. 7: 3695-3702.

Black, M. M., and L. A. Greene (1982) Changes in the colchicine susceptibility of microtubules associated with neurite outgrowth: Studies with nerve growth factor responsive PC12 pheochromocytoma cells. J. Cell Biol. 95: 379-386.

Black, M. M., and P. Keyser (1987) Acetylation of $\alpha$-tubulin in cultured neurons and the induction of $\alpha$-tubulin acetylation in $\mathrm{PC} 12$ cells by treatment with nerve growth factor. J. Neurosci. 7: 1833-1842.

Black, M. M., and J. T. Kurdyla (1983) Post-translational modification of tubulin in cultured neurons. Brain Res. 289: 355-357.

Black, M. M., and V. M.-Y. Lee (1988) Phosphorylation of neurofilament proteins in intact neurons: Demonstration of phosphorylation in cell bodies and axons. J. Neurosci. 8: 3296-3305.

Black, M. M., M. Cochran, and J. T. Kurdyla (1984) Solubility properties of neuronal tubulin: Evidence for labile and stable microtubules. Brain Res. 295: 255-263.

Black, M. M., J. M. Aletta, and L. A. Greene (1986a) Regulation of microtubule composition and stability during nerve growth factor promoted neurite outgrowth. J. Cell Biol. 103: 545-557.

Black, M. M., P. Keyser, and E. Sobel (1986b) Interval between the synthesis and assembly of cytoskeletal proteins in cultured neurons. J. Neurosci. 6: 1004-1012.

Bonner, W. M., and R. A. Laskey (1974) A film detection method for tritium-labeled proteins and nucleic acids in polyacrylamide gels. Eur. J. Biochem. 46: 83-88. 
Brady, S. T., M. Tytell, and R. J. Lasek (1984) Axonal transport and axonal tubulin: Biochemical evidence for cold-stability. J. Cell Biol. 99: 1716-1724

Cambray-Deakin, M. A. and R. D. Burgoyne (1987) Posttranslational modifications of $\alpha$-tubulin: Acetylated and detyrosinated forms in axons of rat cerebellum. J. Cell Biol. 104: 1569-1574.

Drubin, D. G., S. C. Feinstein, E. M. Shooter, and M. W. Kirschner (1985) Nerve growth factor-induced neurite outgrowth in PC12 cells involves the coordinate induction of microtubule assembly and assembly-promoting factors. J. Cell Biol. 101: 1799-1807.

Field, D. J., and J. C. Lee (1985) Isoelectric focusing and two-dimensional electrophoresis of tubulin using immobilized $\mathrm{pH}$ gradients under denaturing conditions. Anal. Biochem. 144: 584-592.

Gozes, I., and K. J. Sweadner (1981) Multiple tubulin forms are expressed by a single neuron. Nature 294: $477-480$.

Greene, L. A., and A. Tischler (1976) Establishment of a noradrenergic clonal line of rat adrenal pheochromocytoma cells which respond to nerve growth factor. Proc. Nat1. Acad. Sci. USSA 73: 2424-2428.

Gunderson, G. G., S. Khawaja, and J. C. Bulinski (1987) Postpolymerization detyrosination of $\alpha$-tubulin: A mechanism for subcellular differentiation of microtubules. J. Cell Biol. 105: 251-264.

Jacobs, J. R., and J. K. Stevens (1986a) Changes in the organization of the neuritic cytoskeleton during nerve growth factor-activated differentiation of PC12 cells: A serial electron microscopic study of the development and control of neuritic shape. J. Cell Biol. 103: 895906.

Jacobs, J. R., and J. K. Stevens (1986b) Experimental modification of PC12 neurite shape with the microtubule-depolymerizing drug nocodazole: A serial electron microscopic study of neurite shape control. J. Cell Biol. 103: 907-915.

Jacobs, J. R., and J. K. Stevens (1987) Dynamics of behavior during neuronal morphogenesis in culture. Cell Motility Cytoskel. 8: 250260.

Laemmli, U. K. (1970) Cleavage of structural proteins during the assembly of the head of bacteriophage $T_{4}$. Nature 227: 680-685.

Lee, V. M.-Y., M. J. Carden, W. W. Schlaepfer, and J. Q. Trojanowski (1987) Monoclonal antibodies distinguish several differentially phosphorylated states of the two largest rat neurofilament subunits (NF-H and NF-M) and demonstrate their existence in the normal nervous system of adult rats. J. Neurosci. 7: 3474-3488.

L'Hernault, S. W., and J. L. Rosenbaum (1983) Chlamydomonas $\alpha$-tubulin is posttranslationally modified in the flagella during flagellar assembly. J. Cell Biol. 97: 258-263.

Maruta, H., K. Greer, and J. L. Rosenbaum (1986) The acetylation of alpha-tubulin and its relationship to the assembly and disassembly of microtubules. J. Cell Biol. 103: 571-579.

Mitchison, T., and M. Kirschner (1984) Dynamic instability of microtubule growth. Nature 312: 237-242.
Morris, J. R., and R. J. Lasek (1982) Stable polymers of the axonal cytoskeleton. J. Cell Biol. 92: 192-198.

Peng, I., L. I. Binder, and M. M. Black (1985) Cultured neurons contain a variety of microtubule-associated proteins. Brain Res. 361: 200211.

Piperno, G., and M. T. Fuller (1985) Monoclonal antibodies specific for an acetylated form of $\alpha$-tubulin recognize antigens in cilia and flagella from a variety of organisms. J. Cell Biol. 101: 2085-2094.

Piperno, G., M. LeDizet, and X. Chang (1987) Microtubules containing acetylated $\alpha$-tubulin in mammalian cells in culture. J. Cell Biol. 104: 289-302.

Purves, D., and R. D. Hadley (1985) Changes in the dendritic branching of adult mammalian neurons revealed by repeated imaging in situ. Nature 315: 404-406.

Rall, W., and I. Segev (1988) Synaptic integration and excitable dendritic spine clusters: Structure/function. In Intrinsic Determinants of Neuronal Form and Function, R. J. Lasek and M. M. Black, eds., pp. 263-282, Liss, New York.

Rothwell, S. W., W. A. Grasser, H. N. Baker, and D. B. Murphy (1987) The relative contributions of polymer annealing and subunit exchange to microtubule dynamics in vitro. J. Cell Biol. 105: 863-874.

Saxton, W. M., D. L. Stemple, R. J. Leslie, E. D. Salmon, M. Zavortink, and J. R. McIntosh (1984) Tubulin dynamics in cultured mammalian cells. J. Cell Biol. 99: 2175-2186.

Schulze, E., and M. Kirschner (1986) Microtubule dynamics in interphase cells. J. Cell Biol. 102: 1020-1031.

Schulze, E., and M. Kirschner (1987) Dynamic and stable populations of microtubules in cells. J. Cell Biol. 104: 277-288.

Sheir-Neiss, G., M. H. Lai, and N. R. Morris (1978) Identification of a gene for $\beta$-tubulin in Aspergillis nidulans. Cell 15:639-647.

Stevens, J. K., J. Trogadis, and J. R. Jacobs (1988) Development and control of axial neurite form: A serial electron microscopic analysis. In Intrinsic Determinants of Neuronal Form and Function, R. J. Lasek and M. M. Black, eds., pp. 115-146, Liss, New York.

Thompson, W. C., D. J. Asai, and D. H. Carney (1984) Heterogeneity among microtubules of the cytoplasmic microtubule complex detected by a monoclonal antibody to alpha tubulin. J. Cell Biol. 98: $1017-1025$

Towbin, H., T. Staehelin, and J. Gordon (1979) Electrophoretic transfer of proteins from polyacrylamide gels to nitrocellulose sheets: Procedure and some applications. Proc. Natl. Acad. Sci. USA 76: 43504354.

Webster, D. R., D. G. Gunderson, J. C. Bulinski, and G. G. Borisy (1987) Assembly and turnover of detyrosinated tubulin in vivo. J. Cell Biol. 105: 265-276.

Webster, D. R., D. G. Gunderson, J. C. Bulinski, and G. G. Borisy (1988) Differential turnover of tyrosinated and detyrosinated microtubules. Proc. Natl. Acad. Sci. USA 84: 9040-9044. 